\title{
Electrochemical determination of 8-oxoguanine in the presence of uric acid
}

\author{
Isabel Rebelo, José António P. Piedade, Ana Maria Oliveira Brett* \\ Departamento de Química, Faculdade de Ciências e Tecnologia, Universidade de Coimbra, 3004-535 Coimbra, Portugal
}

Received 23 June 2003; received in revised form 10 November 2003; accepted 20 November 2003

\begin{abstract}
The electrochemical oxidation of 8-oxoguanine (8-oxoG) in the presence of uric acid (UA) was studied by differential pulse voltammetry over a wide $\mathrm{pH}$ range $(1-12)$. The results showed that both compounds follow a $\mathrm{pH}$-dependent oxidation mechanism that involves two electrons and two protons corresponding to reversible charge transfer reactions. The difference between the peak potential for the oxidation of each analyte was found to be always less than $100 \mathrm{mV}$ over the whole $\mathrm{pH}$ range, the separation being greater in the $\mathrm{pH}$ interval $4-7$. In mixtures of both analytes, $\mathrm{pH} 6$ was shown to be the best for 8-oxoG determination in the presence of uric acid, since the peak current is higher and a greater peak separation is achieved.
\end{abstract}

(C) 2004 Elsevier B.V. All rights reserved.

Keywords: 8-Oxoguanine; Uric acid; Oxidation; Voltammetry; Differential pulse voltammetry

\section{Introduction}

DNA is under constant attack from free radical species leading to the occurrence of multiple modifications, including base-free sites and oxidised bases that are potentially mutagenic [1]. Guanine is the most easily oxidised base in DNA and the major product of guanine oxidation is 8 -oxoguanine ( 8 -oxoG), which is widely accepted as a biomarker of DNA oxidative damage [2]. Elevated levels of 8-oxoG were found in urine of smokers and patients with several diseases including cancer, immunodeficiency syndrome and neurodegnerative diseases [3]. Endogenous production of 8-oxoG due to aerobic cellular metabolism leads to basal levels of one 8 -oxoG/ $10^{6}$ DNA bases, being excreted into urine at basal concentrations below $100 \mathrm{nM}$ [4]. The assessment of 8-oxoG in urine provides a non-invasive approach to evaluate the extent of DNA oxidative damage and DNA repair. Due to their high sensitivity, voltammetric techni-

\footnotetext{
* Corresponding author. Tel./fax: +351-239-835-295.

E-mail address: brett@ci.uc.pt (A.M. Oliveira Brett).
}

ques enable the detection of such low concentrations of 8-oxoG [5].<smiles>Nc1nc2[nH]c(=O)[nH]c2c(=O)[nH]1</smiles>

8 -oxoG<smiles>O=c1[nH]c(=O)c2[nH]c(=O)[nH]c2[nH]1</smiles>

UA
In urine, purines such as uric acid (UA) are co-excreted in concentrations $10^{4}$-fold higher than 8 -oxoG. UA is the major end product of purine metabolism in humans and its levels in urine are also indicative of various diseases. Uric acid has a structure very similar to 8 -oxoG and is thus a strong interferent.

In this work, the dependence of the oxidation peak potential of both substances with $\mathrm{pH}$ over the $\mathrm{pH}$ range $1-12$ was studied by differential pulse voltammetry in order to optimise the experimental conditions and $\mathrm{pH}$ interval for good voltammetric separation of these compounds. 


\section{Experimental}

Solutions of $5 \mu \mathrm{M}$ 8-oxoG, $5 \mu \mathrm{M}$ UA and equimolar 5 $\mu \mathrm{M}$ mixtures of 8-oxoG and UA were prepared by direct dilution of the appropriate volume from stock solutions in sodium acetate, phosphate or borate buffer according to the $\mathrm{pH}$ desired. In all cases buffer electrolyte solutions of ionic strength 0.1 were used and were prepared using analytical grade reagents (Sigma-Aldrich, Madrid) and purified water from a Millipore Milli-Q system (conductivity $<0.1 \mu \mathrm{S} \mathrm{cm} \mathrm{cm}^{-1}$ ).

All voltammetric experiments were performed using a $\mu$ Autolab running with GPES version 4.9 software, EcoChemie, Utrecht, The Netherlands. A glassy carbon electrode (GCE) $(d=6 \mathrm{~mm})$ as working electrode, a Pt wire as counter electrode and a saturated calomel electrode (SCE) as reference electrode, were used in a $10 \mathrm{ml}$ one compartment electrochemical cell. The differential pulse voltammetry [6] experimental conditions were:, pulse amplitude $50 \mathrm{mV}$, pulse width $70 \mathrm{~ms}$, scan rate $5 \mathrm{mV} \mathrm{s}^{-1}$. All potentials are referred to SCE.

\section{Results and discussion}

The differential pulse voltammograms of a $5 \mu \mathrm{M}$ solution of 8-oxoG, UA and a $5 \mu \mathrm{M}$ equimolar mixture of 8 -oxoG and UA in $\mathrm{pH} 6.2,0.1 \mathrm{M}$ phosphate buffer and in $\mathrm{pH} 9.4,0.1 \mathrm{M}$ sodium borate buffer, respectively, are presented in Fig. 1A and B.

The oxidation of 8-oxoG occurs in $\mathrm{pH} 6.2$ buffer at $+0.36 \mathrm{~V}$ and in $\mathrm{pH} 9.4$ buffer at $+0.13 \mathrm{~V}$. The peak width

A)

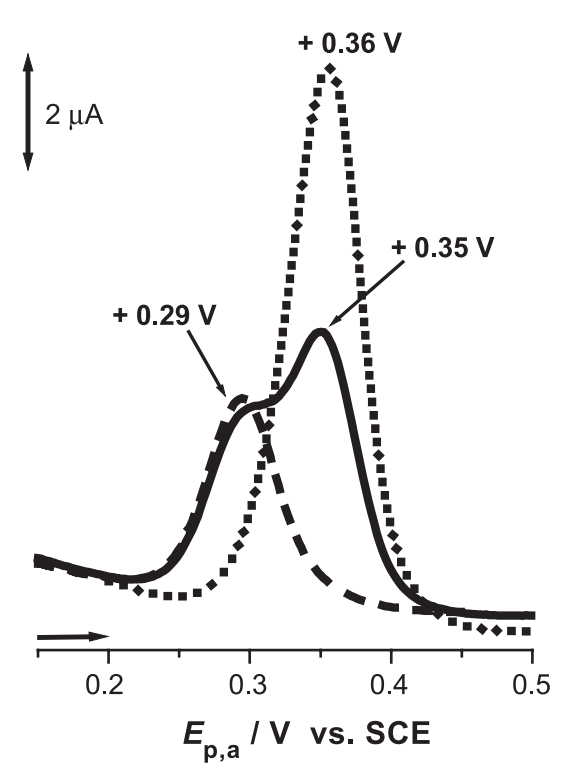

at half height $\left(W_{1 / 2}\right)$ is approximately equal to $58 \mathrm{mV}$ at both $\mathrm{pHs}$ indicating that two electrons are transferred in the oxidation of 8-oxoG, in good agreement with a previous report [5]. UA oxidation occurs in $\mathrm{pH} 6.2$ buffer at $+0.29 \mathrm{~V}$ and in $\mathrm{pH} 9.4$ buffer at $+0.09 \mathrm{~V}$. Also $W_{1 / 2}$ is approximate $58 \mathrm{mV}$ indicating the transfer of two electrons in the UA oxidation. However, at all $\mathrm{pHs}$ and for the same concentration, 8-oxoG always gives a peak with higher current than UA.

In an equimolar mixture of 8-oxoG and $\mathrm{UA}$ at $\mathrm{pH} 6.2$, the oxidation peak potential values are separated by less than $100 \mathrm{mV}$ (Fig. 1A), which compromises their simultaneous detection. The mixture at $\mathrm{pH} 9.4$ (Fig. 1B) presents only one peak with a potential close to that of 8 -oxoG, and it is not possible to separate the peak from UA. The separation between the oxidation peaks is very reproducible over the whole $\mathrm{pH}$ range and a maximum peak separation of $60 \mathrm{mV}$ is achieved in the $\mathrm{pH}$ range $4-7$, as can be seen in Fig. 1A.

It is shown that, in the mixture, the 8-oxoG peak current decreases substantially compared to that obtained when UA is not present. This indicates a competition effect between both compounds for the active electrode surface.

For a better understanding of the real interference of $\mathrm{UA}$ in the electrochemical determination of 8 -oxoG, the dependence of peak potential and peak current for oxidation of both substances with $\mathrm{pH}$ was studied over the range $\mathrm{pH} 1-12$. The purpose was to find at which $\mathrm{pH}$ values the peak separation for these very similar electroactive compounds is maximum and the peak current for UA is comparatively lower in order to minimise its interference. The results obtained are presented in Fig. 2

B)

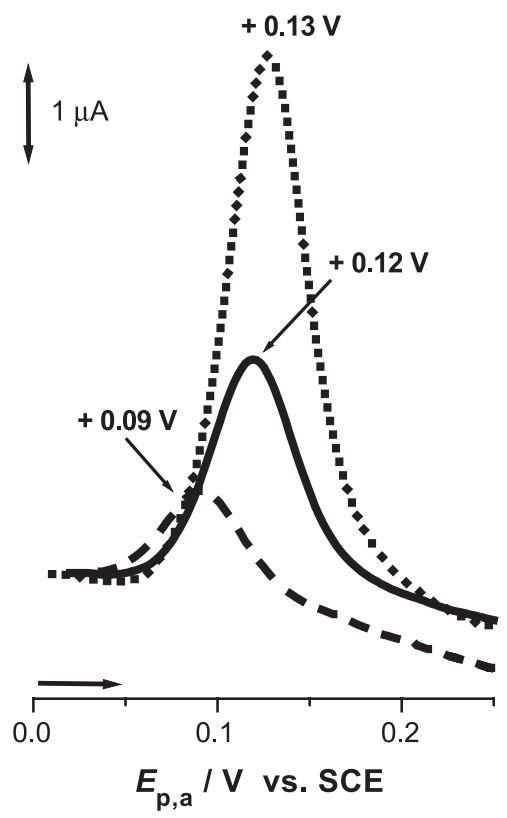

Fig. 1. Differential pulse voltammograms of $5 \mu \mathrm{M}$ solution of (---) 8-oxoG, (- - -) UA and (-) $5 \mu \mathrm{M}$ equimolar mixture of 8-oxoG and UA in: (A) pH 6.2, 0.1 $\mathrm{M}$ phosphate buffer and (B) $\mathrm{pH} 9.4,0.1 \mathrm{M}$ sodium borate buffer. Pulse amplitude $50 \mathrm{mV}$, pulse width $70 \mathrm{~ms}$ and scan rate $5 \mathrm{mV} \mathrm{s}^{-1}$. 
A)

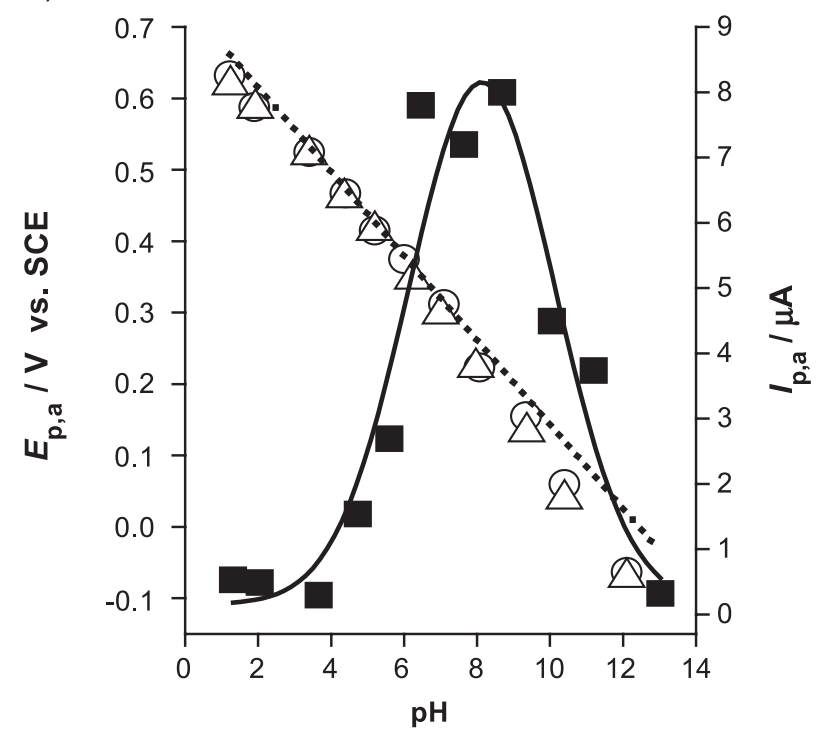

B)

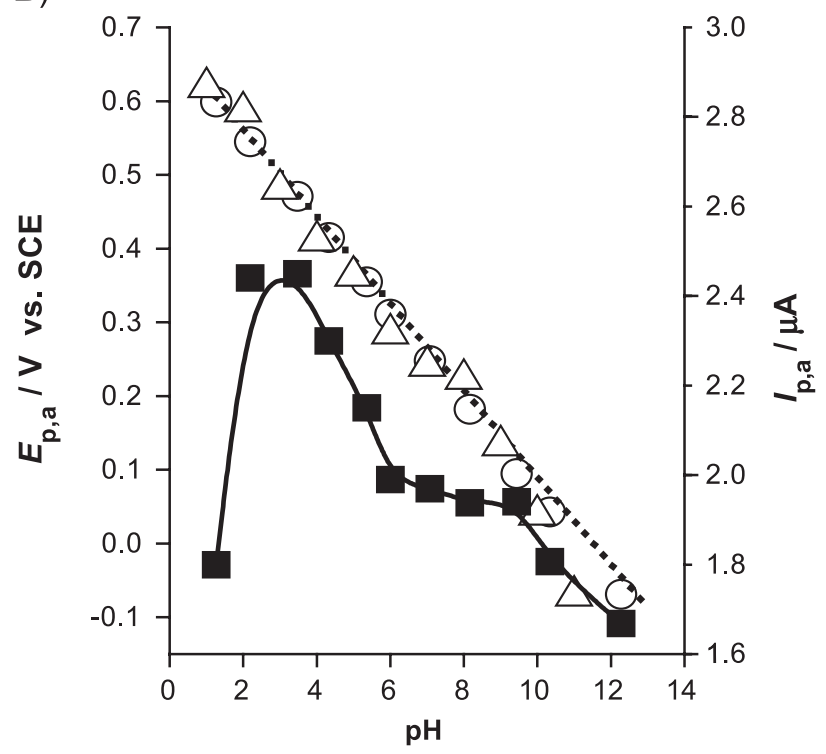

Fig. 2. Plot of $E_{\mathrm{pa}}(\mathrm{O})$ and $I_{\mathrm{pa}}\left(\begin{array}{l}1 \\ 1\end{array}\right) \mathrm{vs}$. $\mathrm{pH}$ for $5-\mu \mathrm{M}$ solutions of (A) 8-oxoG and (B) UA, together with plots of $E_{\mathrm{pa}}(\triangle)$ vs. pH for $5 \mu \mathrm{M}$ equimolar mixture of both compounds. Dotted lines slope $59 \mathrm{mV}$ per $\mathrm{pH}$ unit.

and show that peak current for 8 -oxoG is maximum in the $\mathrm{pH}$ range 6-8 (Fig. 2A), while for UA, higher peak currents are obtained at $\mathrm{pH}$ lower than 5 (Fig. 2B). For both analytes, the peak potential follows a linear dependence with $\mathrm{pH}$ with a slope of $59 \mathrm{mV} / \mathrm{pH}$ (Fig. 2A and B). The $\mathrm{pH}$ and nature of the supporting electrolyte influence the peak potentials. With both acetate and phosphate buffers, in the $\mathrm{pH}$ interval of $4-7$, the peak separation is a maximum. Nevertheless, for both substances the variation of peak potential with $\mathrm{pH}$ over the whole range studied still fits to a line of slope $59 \mathrm{mV} / \mathrm{pH}$, meaning that the same number of electrons and protons are involved.
Over the entire $\mathrm{pH}$ range studied, the observed $W_{1 / 2}$ for each analyte is close to $60 \mathrm{mV}$, which, together with the $\mathrm{pH}$ dependent oxidation peak potential, leads to the conclusion that both compounds follow a reversible charge transfer mechanism that involves two electrons and two protons.

The behaviour of equimolar mixtures of both analytes was studied, and it was observed that the presence of UA does not interfere significantly with the peak potential for 8-oxoG oxidation. Nevertheless, a small shift to a lower potential of the 8 -oxoG peak when UA is present was observed. This is shown in Fig. 2A, a plot of the 8-oxoG peak potential $\mathrm{pH}$ dependence in the absence or presence of UA, and in Fig. 2B, is presented the UA peak potential $\mathrm{pH}$ dependence in the absence or presence of 8-oxoG. It is confirmed that it is only possible to distinguish the 8-oxoG oxidation peak from the UA oxidation peak in the $\mathrm{pH}$ range $4-7$, since at all other pHs only one peak could be observed, as shown in Fig. 1.

In mixtures of both compounds, the 8-oxoG peak current decreases substantially when compared with the peak current obtained in the absence of UA. A pH value of 6 is best for 8-oxoG determination since the peak current is bigger and sufficiently good separation between peaks is obtained allowing the electrochemical determination of 8 -oxoG in the presence of uric acid to be achieved. It was possible using the optimised experimental conditions to obtain a detection limit of 10 fmol for 8-oxoG in the presence of UA in standard mixtures [7].

\section{Conclusions}

8-oxoG has very similar voltammetric behaviour to uric acid. Both compounds follow a $\mathrm{pH}-\mathrm{dependent} \mathrm{oxi-}$ dation mechanism that involves two electrons and two protons corresponding to reversible charge transfer. The $\mathrm{pH}$ ranges for the maximum current and peak separation leads to the conclusion that the $\mathrm{pH}$ range $6-8$ should be used for 8 -oxoG detection in the presence of UA. In mixtures of both compounds, the 8-oxoG peak current decreases substantially when compared with the peak current obtained in the absence of UA and $\mathrm{pH} 6$ showed to be the best for 8-oxoG determination since the peak current is higher and good separation between peaks is achieved.

\section{Acknowledgements}

Financial support from Fundação para a Ciência e Tecnologia (FCT), POCTI (co-financed by the European Community Fund FEDER), ICEMS (Research Unit 103) and European Projects QLK3-2000-01311 and HPRN-CT2002-00186 are gratefully acknowledged. 


\section{References}

[1] B. Halliwell, Oxygen and nitrogen are pro-carcinogens. Damage to DNA by reactive oxygen, chlorine and nitrogen species: measurement, mechanism and the effects of nutrition, Mutat. Res. 443 (1999) 37-52.

[2] ESCOOD (European Standards Committee on Oxidative DNA Damage), Comparisison of different methods of measuring 8-oxoguanine as a marker of oxidative DNA damage, Free Radic. Res. 32 (2000) 333-341.

[3] R. Olinski, D. Gackowski, M. Foksinski, R. Rozalski, K. Roszkowski, P. Jaruga, Oxidative DNA damage: assessment of the role in carcinogenesis, atherosclerosis, and acquired immunodeficiency syndrome, Free Radic. Biol. Med. 33 (2002) 192-200.
[4] A. Weimann, D. Belling, H.E. Poulsen, Quantification of 8-oxo-guanine and guanine as the nucleobase, nucleoside and deoxynucleoside forms in human urine by high-performance liquid chromatography-electrospray tandem mass spectrometry, Nucleic Acids Res. 30 (2002) 1-8.

[5] A.M. Oliveira-Brett, J.A.P. Piedade, S.H.P. Serrano, Electrochemical oxidation of 8-oxoguanine, Electroanalysis 12 (2000) 969-973.

[6] E.P. Parry, R.A. Osteryoung, Evaluation of analytical pulse polarography, Anal. Chem. 37 (1965) 1634-1637.

[7] I.A. Rebelo, J.A.P. Piedade, A.M. Oliveira-Brett, Development of an HPLC method with electrochemical detection of femtomoles of 8-oxo7,8-dihydroguanine and 8-oxo-7,8-dihydro- $2^{\prime}$-deoxyguanosine in the presence of uric acid, Talanta (2003) (in press). 